\title{
Motion Cueing Algorithm Online Parameter Switching in a Blink of an Eye - A Time-Variant Approach
}

Tobias Lorenz 


\section{Content}

I. Introduction

7 German Aerospace Center (DLR)

7 Institute of Transportation Systems (TS)

7 The Dynamic Driving Simulator at TS

$>$ The Motion Cueing at TS

II. Motivation and Goals

III. Problems with the Parameter Switching

IV. The State Adaption Method

V. Constraints for the Parameter Switching

VI. Conclusion and Next Steps 


\section{Introduction}




\section{Introduction}

\section{German Aerospace Center (DLR)}

Areas of Research

$>$ Aeronautics

7 Space

$>$ Transport

$>$ Energy
DLR in numbers

7 Budget:

2006 1.168 M Euro

2007 1.224 M Euro

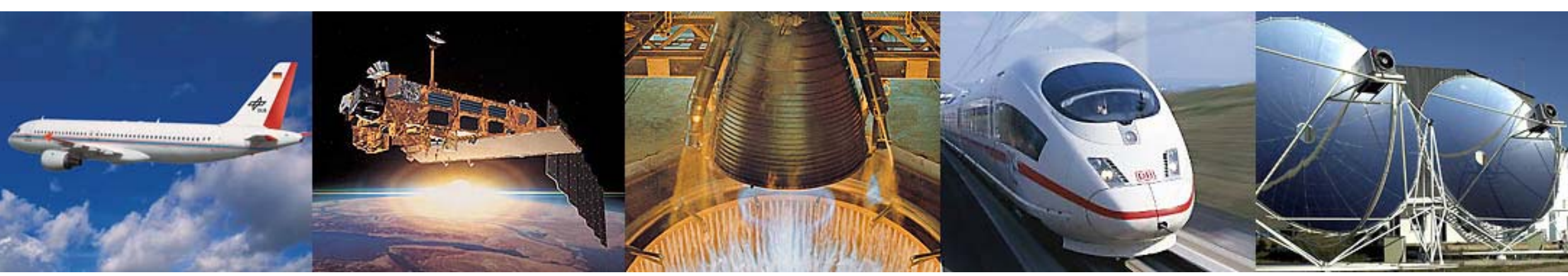




\section{Introduction DLR - Locations and Employees}

5.600 employees work at 28 research institutes and facilities at 13 locations.

Offices in Brussels, Paris and Washington.

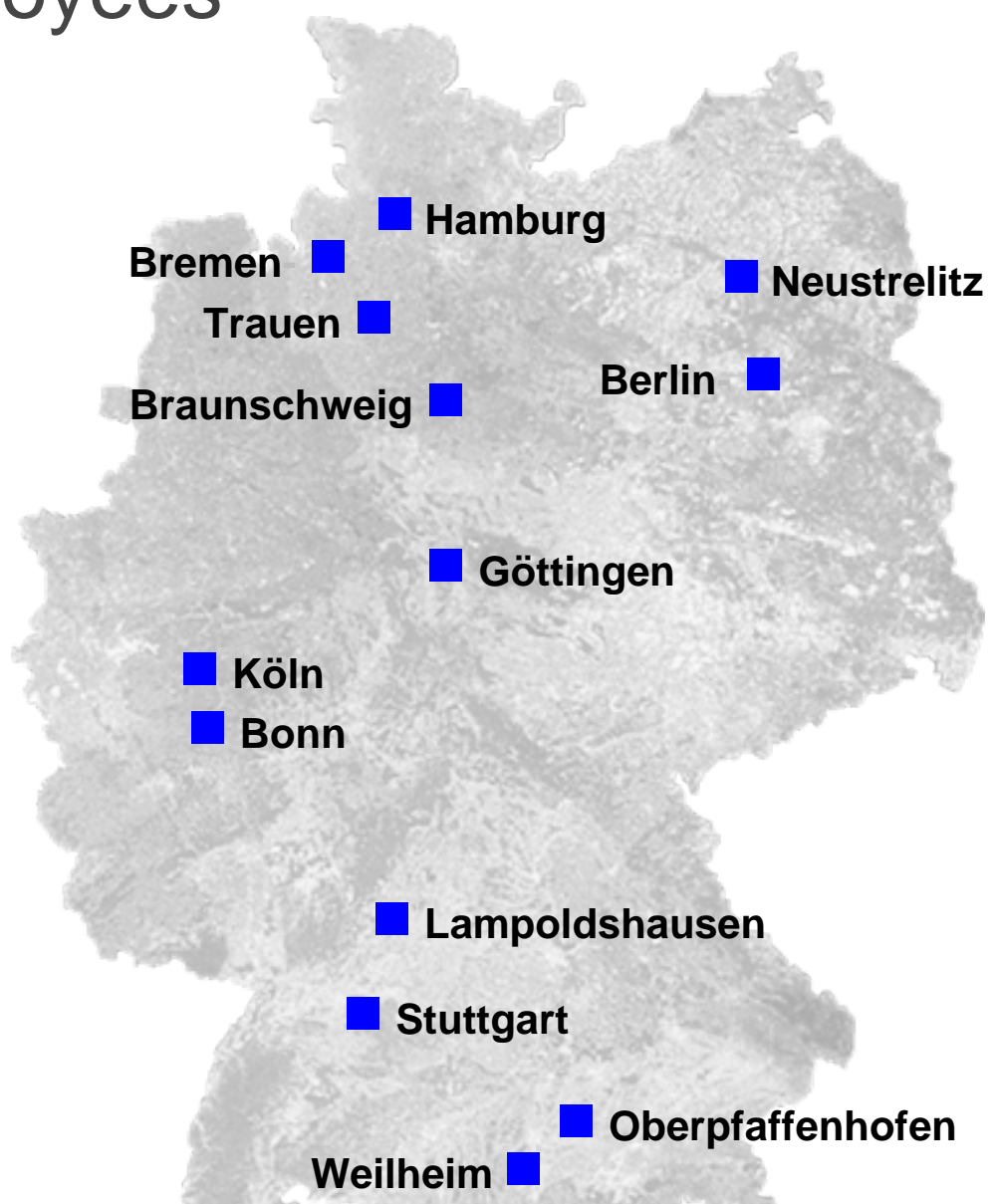




\section{Introduction}

\section{Transportation - Participating institutes}

$>$ Institute of Transport Research

$>$ Project Transport Studies

7 Institute of Transportation Systems

$>$ Institute of Vehicle Concepts

... and 21 more institutes from aeronautics, space and energy

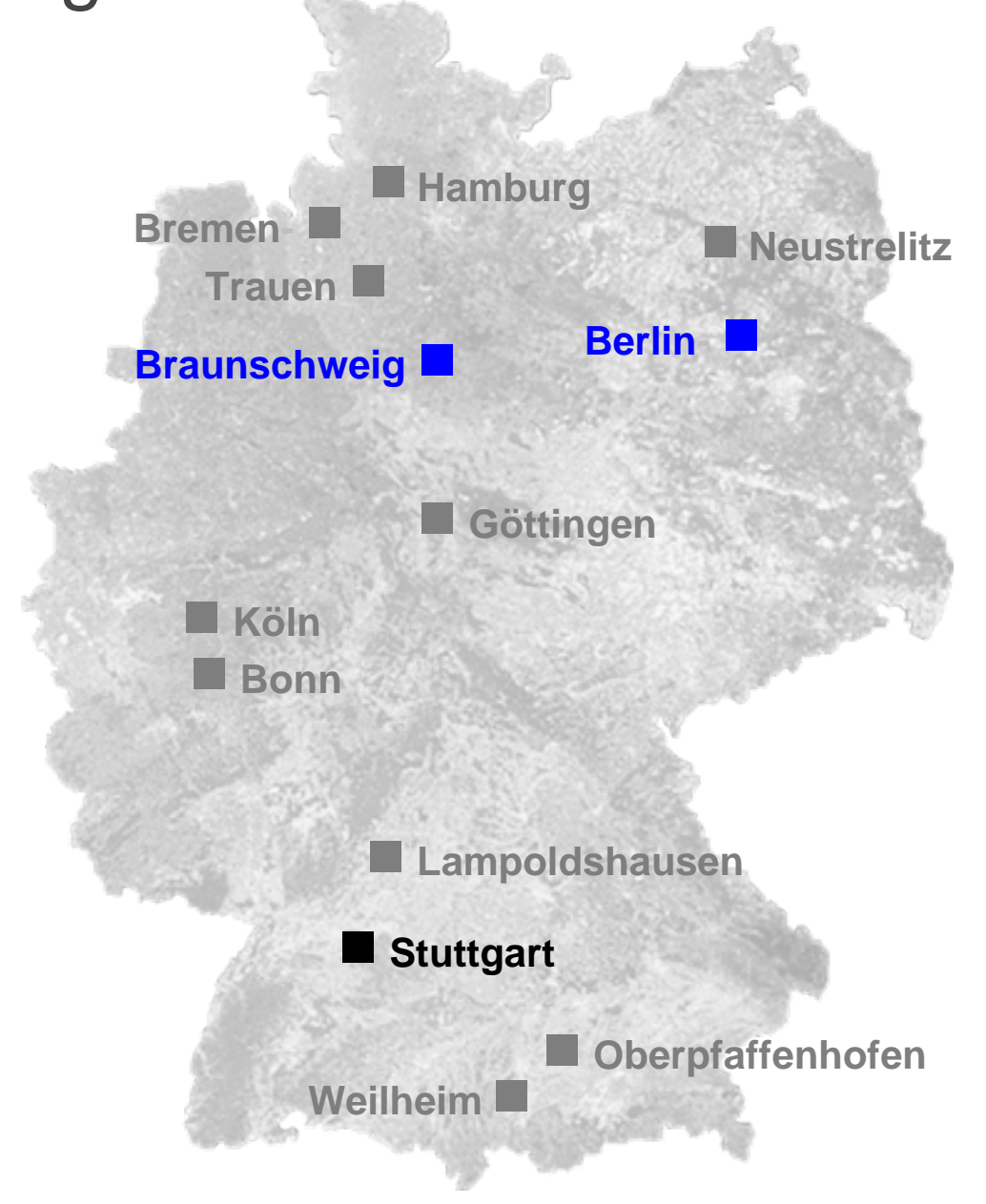




\section{Introduction}

\section{Institute of Transportation Systems}

Residence:

Since:

Director:

Employees:
Braunschweig and Berlin

March 2001

Prof. Dr.-Ing. Karsten Lemmer

Presently 100 employees

from various scientific disciplines

Range of tasks

$>$ Basic research

$>$ Creating concepts and strategies

$>$ Prototype development

Fields of Research

$>$ Automotive

$>$ Railway Systems

$>$ Traffic Management 


\section{Introduction}

\section{The Dynamic Driving Simulator at TS}

7 Hexapod - Moving Base

$>$ The simulator platform is moved by extending and retracting the 6 hydraulic cylinders

$>$ Moved mass is approximately $6000 \mathrm{~kg}$

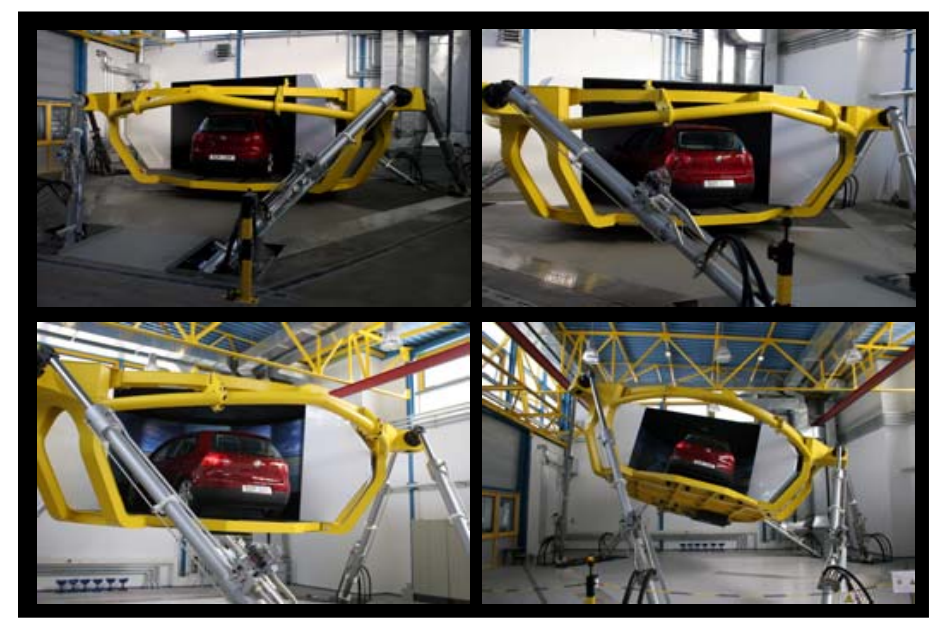

\begin{tabular}{|l|l|l|l|}
\cline { 2 - 4 } \multicolumn{1}{c|}{} & Length / Angle & Velocity & Acceleration \\
\hline Longitudinal & $\pm 1,5 \mathrm{~m}$ & $\pm 2 \mathrm{~m} / \mathrm{s}$ & $\pm 10 \mathrm{~m} / \mathrm{s}^{2}$ \\
\hline Lateral & $\pm 1,4 \mathrm{~m}$ & $\pm 2 \mathrm{~m} / \mathrm{s}$ & $\pm 10 \mathrm{~m} / \mathrm{s}^{2}$ \\
\hline Vertical & $\pm 1,4 \mathrm{~m}$ & $\pm 2 \mathrm{~m} / \mathrm{s}$ & $\pm 10 \mathrm{~m} / \mathrm{s}^{2}$ \\
\hline Roll & $-20^{\circ} /+21^{\circ}$ & $\pm 50 \% / \mathrm{s}$ & $\pm 250 \% / \mathrm{s}^{2}$ \\
\hline Pitch & $\pm 21^{\circ}$ & $\pm 50 \% / \mathrm{s}$ & $\pm 250 \% / \mathrm{s}^{2}$ \\
\hline Yaw & $\pm 21^{\circ}$ & $\pm 50 \% / \mathrm{s}$ & $\pm 250 \% / \mathrm{s}^{2}$ \\
\hline
\end{tabular}


I. Introduction

The Motion Cueing at TS

${ }^{(\mathrm{s})} \underline{\mathrm{FDD}}_{\mathrm{FD}}$
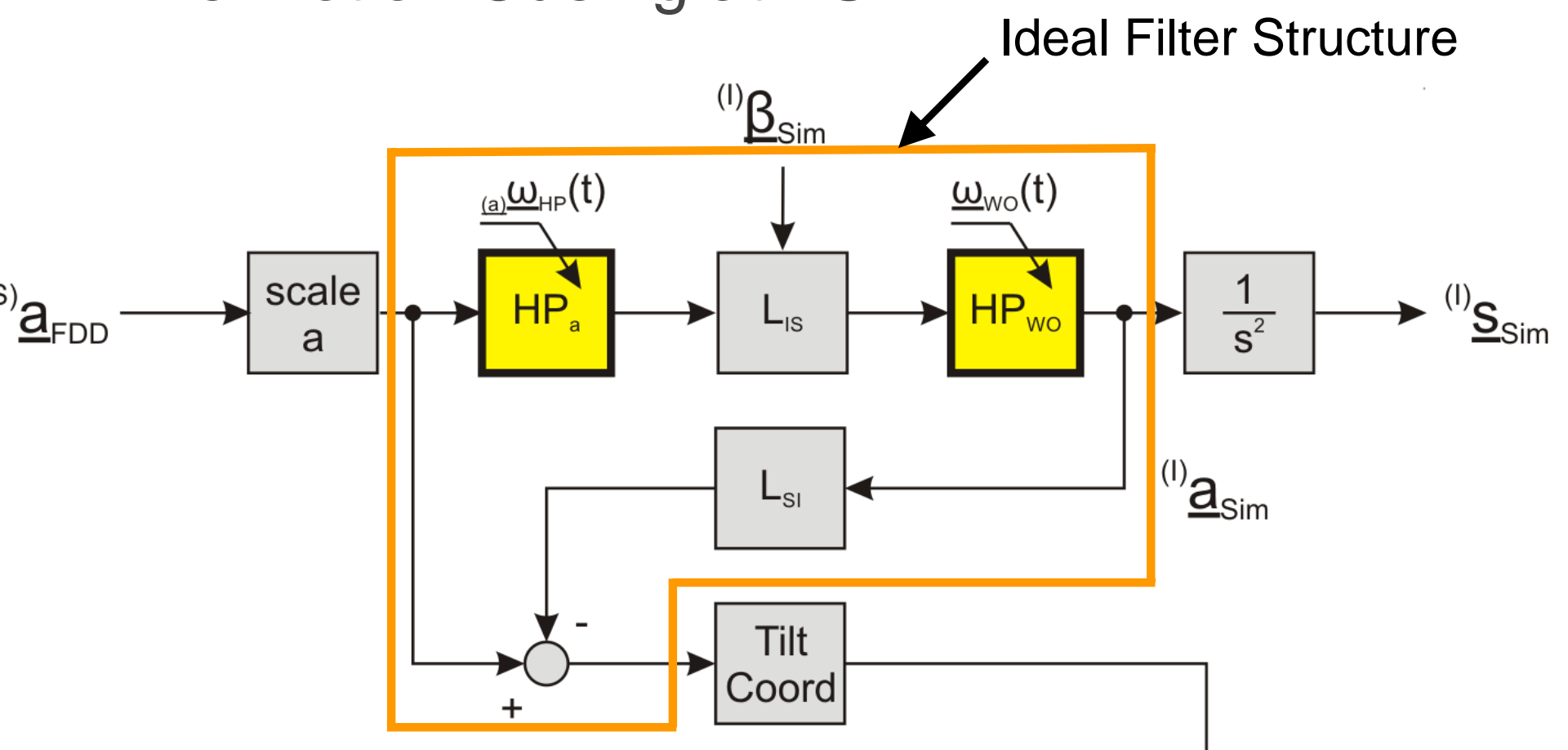

(S)
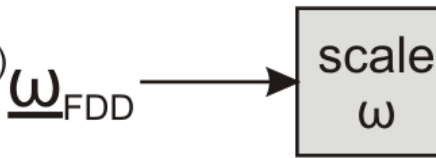

${ }^{(1)} \underline{\beta}_{\text {sim }}$

\section{MCA $\rightarrow$ Fast Tilt Coordination (FTC)}




\section{Motivation and Goals}




\section{Motivation and Goals}

7 In different driving simulator scenarios different characteristic frequencies occur

7 Mainly for the presentation of lateral movement

7 Usually a fixed set of MCA parameters is used within a simulator ride

7 Parameter-Tuning for worst-case scenario

7 Develop a time-variant MCA (based on the FTC approach $\rightarrow$ only high pass filters) enabling a discrete online parameter switching

$>$ Switch the set of MCA parameters according to the current driving situation (city, rural, highway)

$>$ The switching process should not be recognizable by the driver 


\section{Problems with the Parameter Switching}




\section{Problems with the Parameter Switching}

State-Space Description of linear time-variant high-pass filter

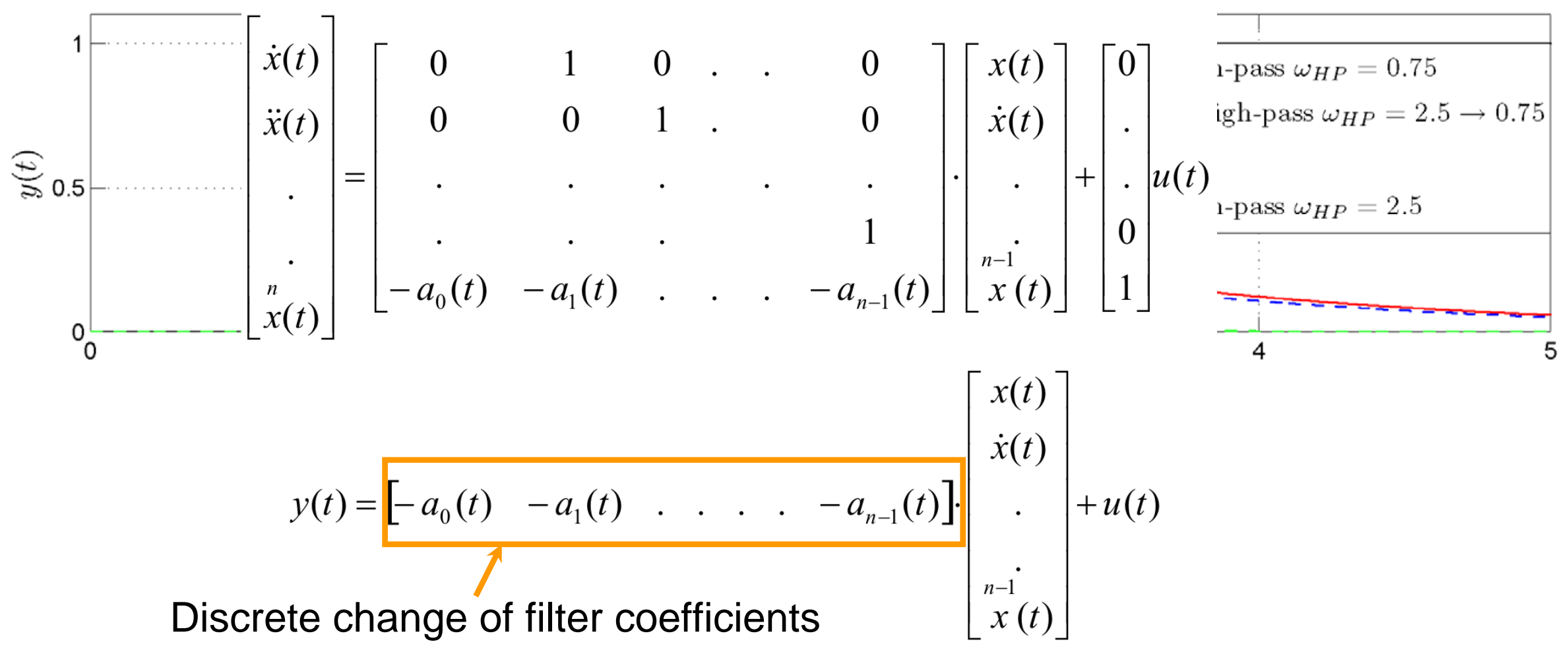




\section{The State Adaption Method}




\section{The State Adaption Method The Theoretical Concept}

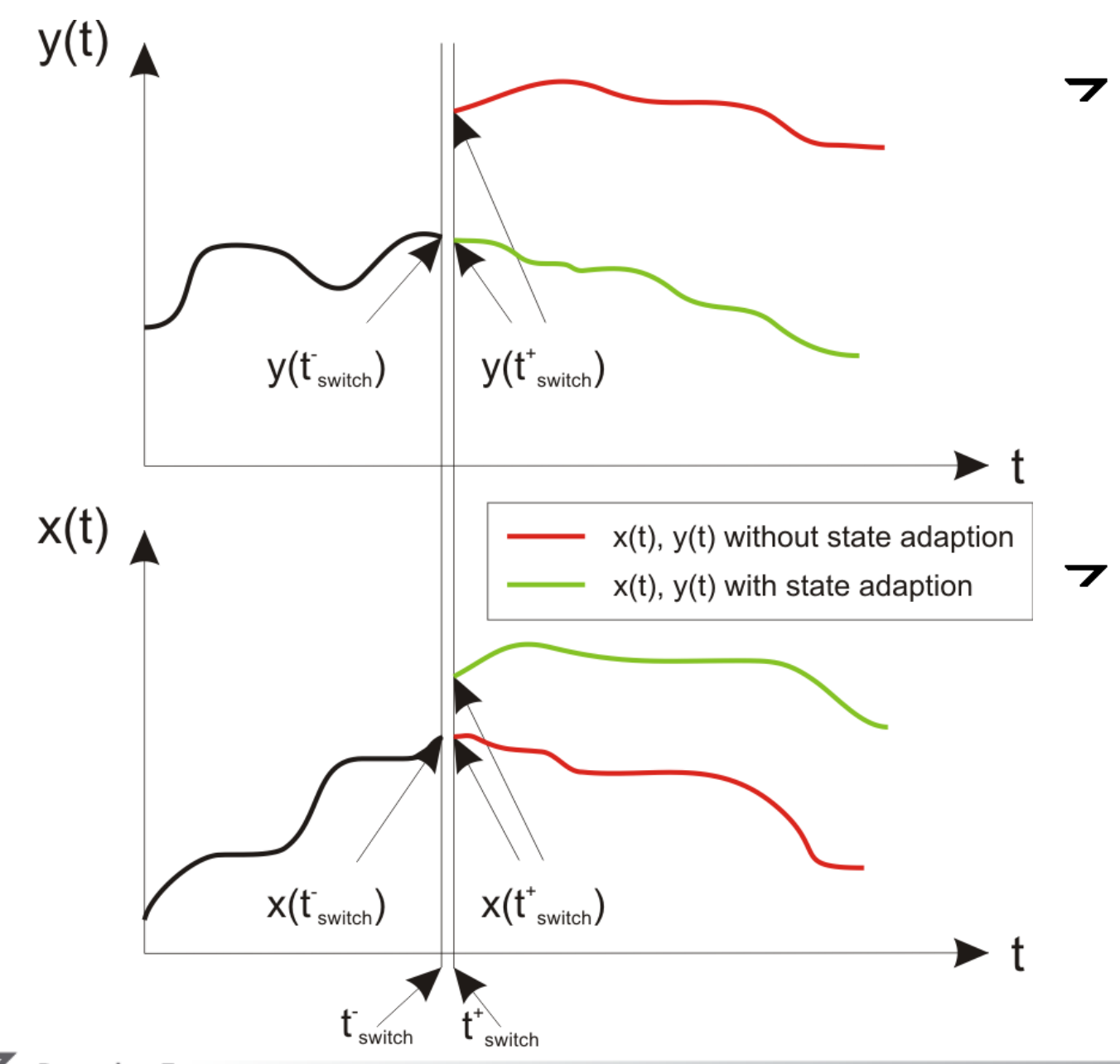

$>$ Concept of the state adaption method for a first order high pass filter

$>$ Instead of having an output signal step this step is mapped to the state space

$>$ Higher order high-pass filters enables the avoidance of discontinuities not only for $\mathrm{y}(\mathrm{t})$ but for its derivatives, too 


\section{The State Adaption Method The Mathematical Concept}

7 Which signals do we know?

$>$ Output signal $\mathrm{y}(\mathrm{t})$ as well as its derivatives

$>$ The states of the high pass filter

$>$ The input signal $u(t)$ as well as its derivatives

$$
\begin{aligned}
& \text { I. } y(t)=-a_{0} \cdot x(t)-\ldots-a_{n-1} \cdot{ }^{(n-1)} x(t)+u(t) \longleftarrow \text { Output equation } \\
& \text { II. } \frac{d y}{d t}=-a_{0} \cdot \frac{d x}{d t}-\ldots-a_{n-1} \cdot{ }^{(n)}(t)+\dot{u}(t)
\end{aligned}
$$




\section{The State Adaption Method}

\section{First Results}

$>$ No discontinuities in the moment of parameter switching

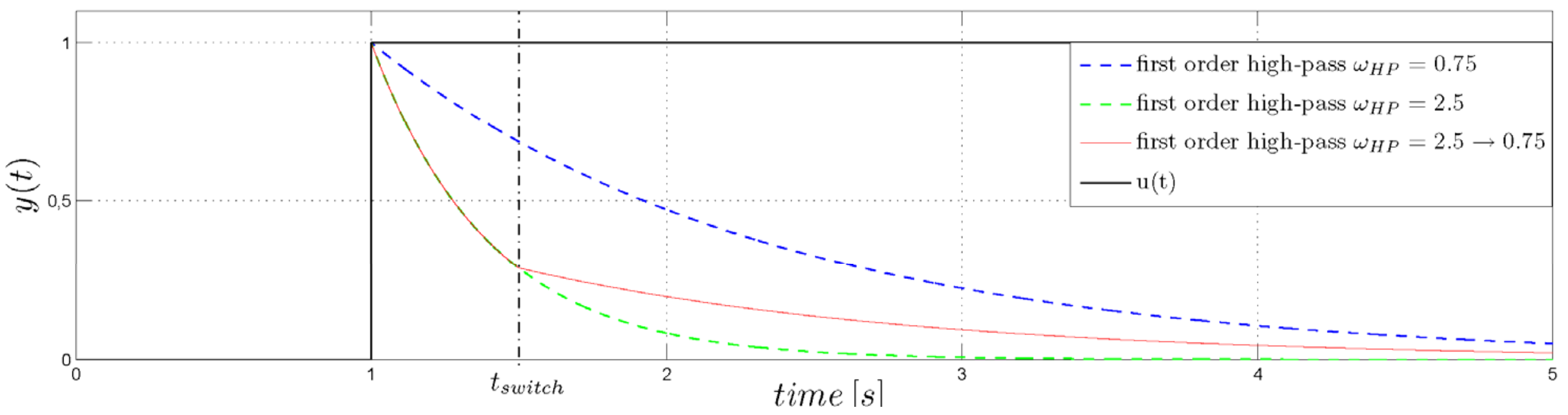




\section{The State Adaption Method Problems within the FTC algorithm}

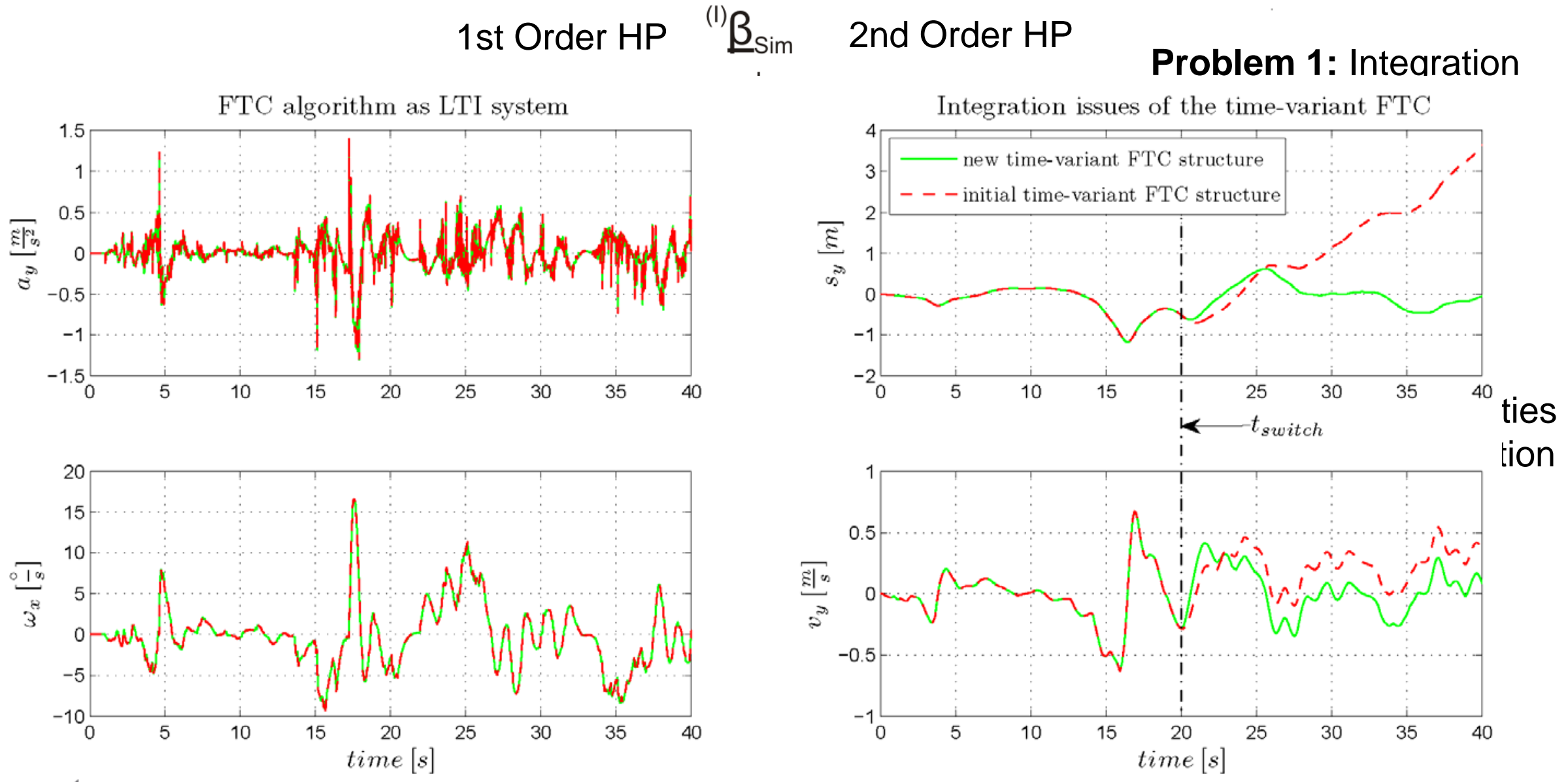




\section{The State Adaption Method The new time-variant FTC structure}

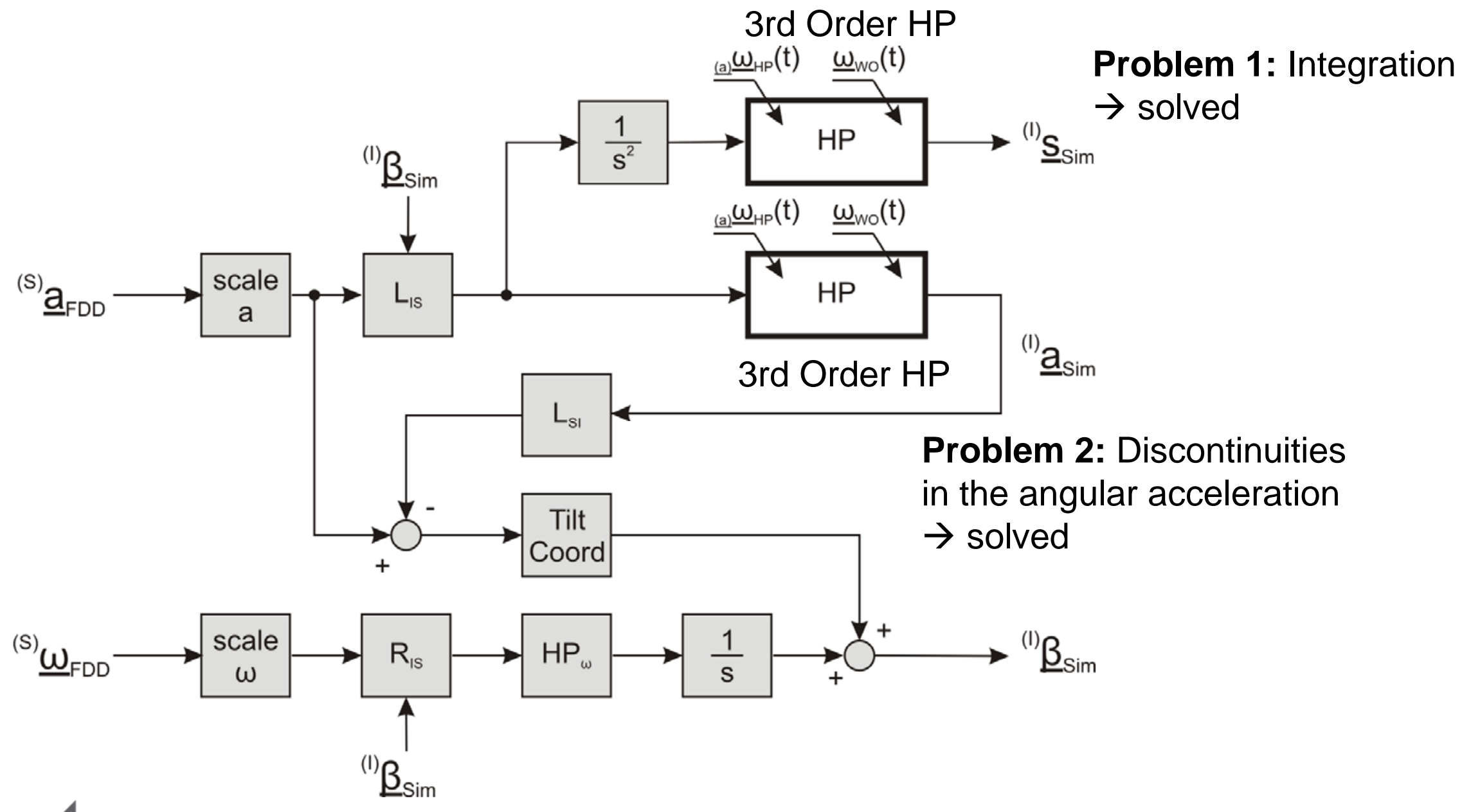




\section{The State Adaption Method The Results}
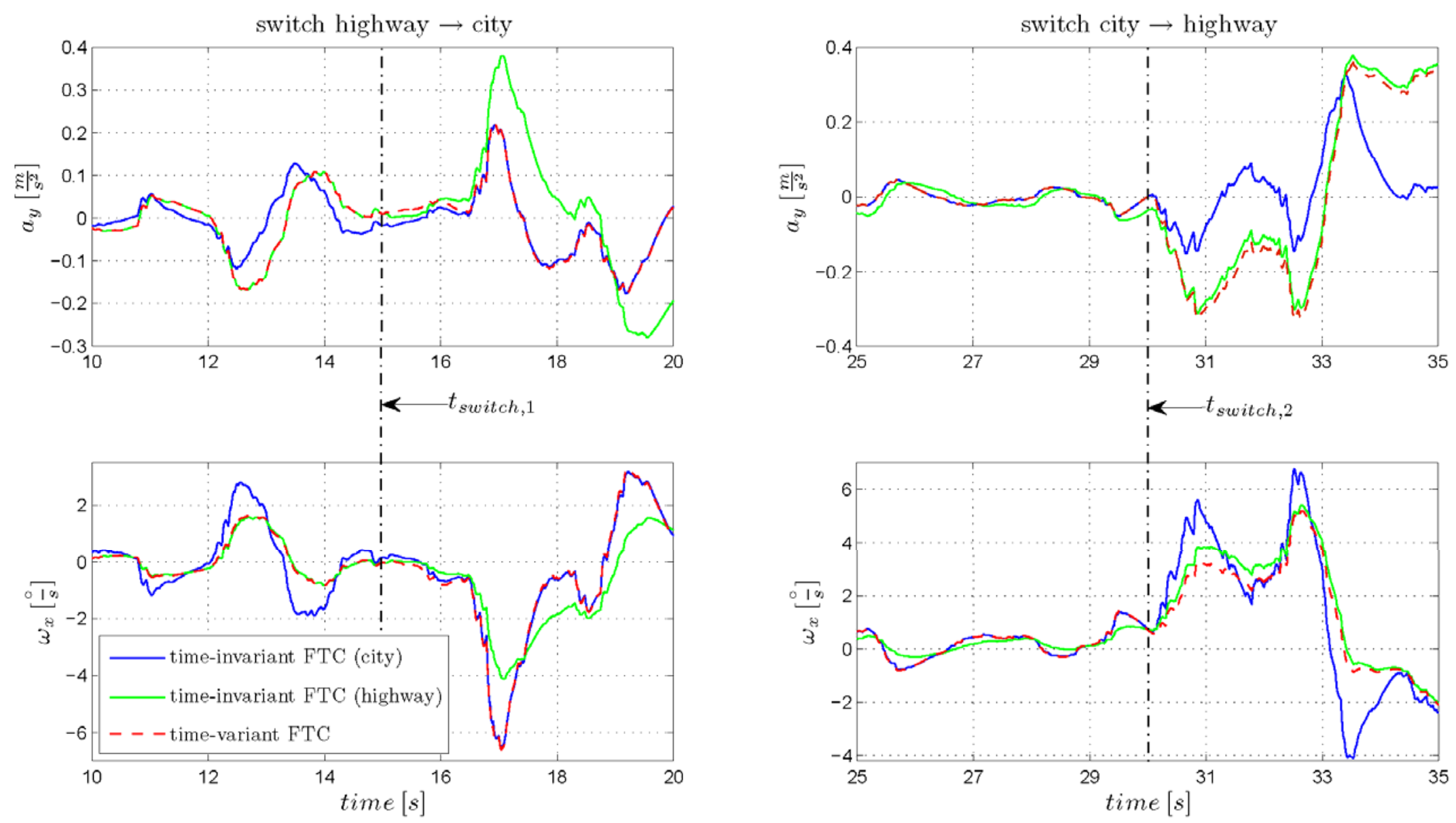


\section{Constraints for the Parameter Switching}




\section{Constraints for the Parameter Switching}

7 Using the state adaption method a discrete online high-pass filter coefficient switching within a single simulation time step is possible but

$>$ There is still an influence on the signal flow of the output signal which should be kept as low as possible $\rightarrow$ Constraints for the initialization of the switching process

$>$ The sets of parameters should be related to superior driving situations $\rightarrow$ avoid to many switching processes

\begin{tabular}{|c|r|r|r|r|r|r|}
\cline { 2 - 6 } \multicolumn{1}{l|}{} & $\left|s_{y}\right|$ & $\left|v_{y}\right|$ & $\left|a_{y}\right|$ & $\left|\phi_{\text {titit }}\right|$ & $\left|\omega_{x, \text { tilt }}\right|$ & $\left|\dot{\omega}_{x, \text { thit }}\right|$ \\
\hline $\operatorname{limits}$ & $\leq 0,1 m$ & $\leq 0,1 \frac{m}{s}$ & $\leq 0,1 \frac{m}{s^{2}}$ & $\leq 1^{\circ}$ & $\leq 2 \frac{\circ}{s}$ & $\leq 2 \frac{\circ}{s^{2}}$ \\
\hline
\end{tabular}




\section{Conclusion and Next Steps}




\section{Conclusion and Next Steps}

$>$ The state adaption method enables the discrete switching of high-pass filter coefficients in an MCA within a single simulation time step

7 Discontinuities in the output signal as well as in its derivatives can be avoided

$>$ The use of switching constraints is necessary to keep the influence of the parameter switching to the output signal as low as possible

$>$ Combine the state adaption method with the method of switching scaling factors

$>$ Run driver studies to proof the advantage of this method 


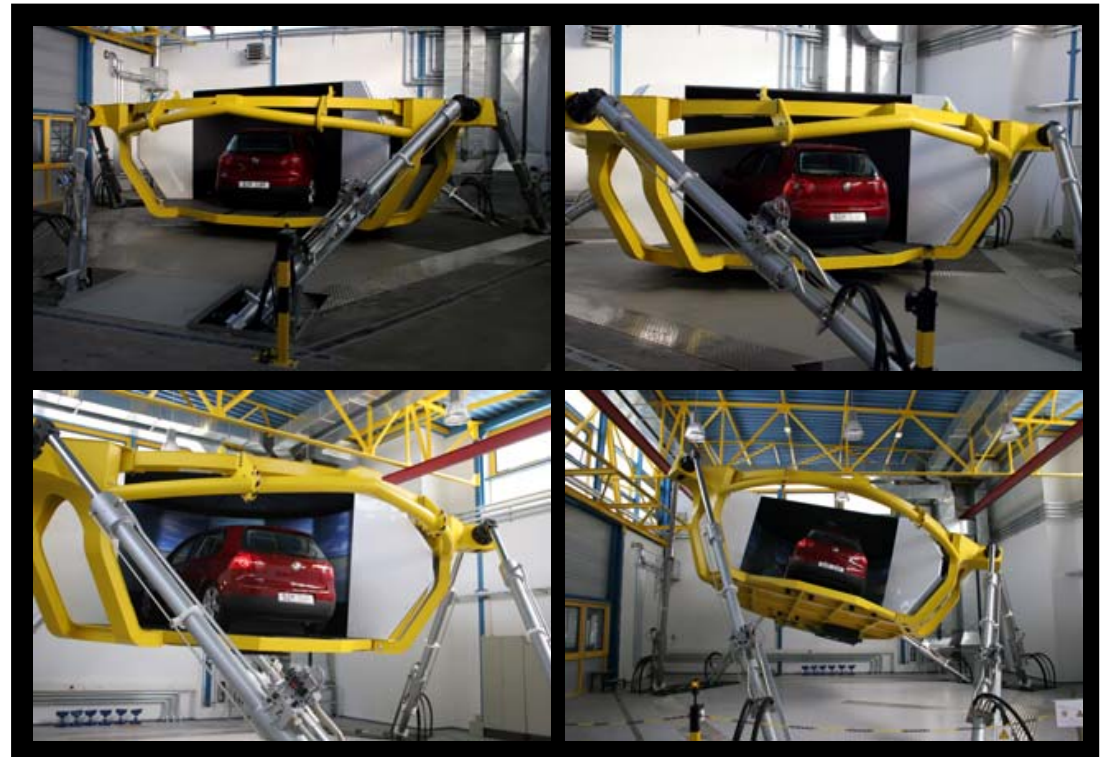

Institute of Transportation Systems Dipl.-Ing. Tobias Lorenz tobias.lorenz@dlr.de 亩 +49531 295-3475 www.dlr.de/ts 